\title{
Means and ends
}

\section{Palaeoclimate research increasingly portrays itself as a means to understanding future climate change. It would serve the science and scientists better to regard the study of the past as an end in its own right.}

Most of us want to know how our involuntary climate change experiment is going to end. But, luckily, that's not all geoscientists want to know. Scientific curiosity is quite rightly not restricted to topics of immediate societal relevance; at least that's what we think at Nature Geoscience. Natural disasters, climate change and human-induced environmental degradation all deserve our attention, but not exclusively.

Contrary to myths that occasionally emerge from the cover letters we receive with manuscript submissions, papers that provide fundamental insights into how the Earth and the other planets of our Solar System work have (at least) an equal chance of passing through our editorial screening, compared with papers that are more directly relevant to society. And, in our experience, they stand the same chance of passing through peer review as well, because our referees share our broad interest in science.

Nevertheless, we observe a tendency for authors who study past climate to spend a significant fraction of their manuscript focused on possible implications for future climate change. Worryingly, this tendency holds even when such implications are painfully tenuous or when our length constraints force the authors to neglect the discussion and interpretation of their hard-earned and beautiful data sets in terms of their core relevance: understanding past climate.

For research funded through taxes, it stands to reason that the public should, by means of the democratic process, have an influence on the research questions that are being tackled. As a consequence, research proposals are under high pressure to demonstrate the immediate societal benefits of the work they seek funding for. Whether or not this is a reasonable approach to doing science, these pressures do not apply in the same way to the publication criteria of scientific journals. True, we can only publish papers that are submitted, and most of these come from publicly funded research. But there is no need for authors to weight their valuable writing space towards speculative implications.

Of course, palaeodata should be used specifically and purposefully to constrain future climate evolution where possible. And we are not arguing that important implications of palaeoclimatic findings for future climate change should be suppressed or played down. Two studies in this issue, by Siddall et al. (on page 571) and by Zeebe et al. (on page 576), are a case in point. However, out of 17 papers published in the area of palaeoclimate in Nature Geoscience this year, only four noted implications for future climate change.

The low proportion of publications on palaeoclimate with relevant insights into future change has many causes. Perhaps the most important reason is that no two periods in the Earth's evolution are the same. For example, for most of the past 2-3 million years of the Earth's history - the timespan that is most similar to today in terms of the position of the continents, and the period that we know most about - global mean temperatures have been colder than today. As a rise in temperature from glacial times to the present day does not necessarily have the same impacts as a warming beyond today's temperatures, it is not straightforward to apply lessons from the cooler past to the coming centuries.

Ultimately, when palaeoclimate scientists highlight their research predominantly in terms of its implications for our climatic future, they send the message that studying past climate dynamics is not a worthwhile endeavour in its own right. They should know better than to undermine the self-esteem of their field.

\section{On track for citations}

\section{Nature Geoscience has entered Thomson Reuters's Journal Citation Report, but so far only the 'immediacy index' has been calculated.}

June is the release time of Thomson Reuters's journal impact factors. The 2008 rankings have now been published, but Nature Geoscience has one more year to go before receiving its full journal impact factor. We have, however, received our 'immediacy index' - a number that ranks journals according to the number of citations their papers have received within the year of publication.

Of the 143 journals listed under the category of 'geosciences, multidisciplinary' Nature Geoscience comes third, after Gondwana Research and Petroleum Geoscience. Furthermore, for those interested in numbers, we would hold the third rank even after correcting for News \& Views articles that cite a paper in the same issue.

In the notoriously slow publishing environment of the Earth sciences, the immediacy index is of limited use. Papers that appear in the second half of the year are unlikely to be cited before the end of the year, because even fast-turnover papers will probably still be working their way through the publishing pipeline.

The journal impact factor, by contrast, is based on the average citations to articles published in the preceding two years.
For Nature Geoscience, having started in 2008, this number will first be available in June 2010, and will be based on the number of citations in 2009 to only one year of Nature Geoscience papers, those published in 2008. Only in 2011 will we receive a fully comparable impact factor based on two years of published papers.

For the reasons above, the immediacy index should be taken with a pinch of salt as a measure of geoscience journal ranking. Nevertheless, we take the encouraging outcome as a sign - from the viewpoint of Nature Geoscience's visibility in the field - that we are on the right track. 